\title{
O Partido Socialista chileno nos 20 anos de Concertación: mudança organizacional, concessões programáticas e crise endógena
}

Augusto Neftali Corte de Oliveira'

\begin{abstract}
Resumo
O artigo apresenta um panorama da participação do Partido Socialista nos 20 anos, em que a Concertación venceu sucessivas eleições presidenciais no Chile, inserindo-se no debate da ciência política sobre organização, objetivos e mudança partidária. Ao lado de pesquisa na literatura sobre o tema, o artigo recorre a periódicos jornalísticos e documentos internos para reconstruir a trajetória do partido. O principal argumento levantado é o de que as mudanças organizacionais e programáticas do Partido Socialista, que estão ligadas ao sistema político chileno e ao objetivo de manutenção da Concertación, afastaram a agremiação de seus mecanismos de inovação endógena. Esse processo refletiu-se em cisões no campo de esquerda do Partido Socialista e favoreceu a derrota da candidatura presidencial da Concertación em 2009/2010.
\end{abstract}

Palavras-chave: Chile. Partido Socialista. Concertación.

\section{Introdução}

Após quatro eleiçóes vitoriosas, que preencheram os primeiros vinte anos da nova democracia do Chile, em 2010 a candidatura presidencial da Concertación de Partidos por la Democracia foi derrotada. Nesse longo período, a coalizáo de centro-esquerda alcançou importantes melhoras para a vida social e política do Chile, com um modelo de gestão econômica reconhecidamente

I Mestre em Ciência Política pela Universidade Federal do Rio Grande do Sul (UFRGS), Porto Alegre, Brasil e Doutorando pelo Programa de Pós-Graduação em Ciência Política da UFRGS. É autor de artigos publicados nas revistas Mediações (UEL, 2011), Revista Eletrônica de Ciência Política (2011) e Debates (UFRGS, 2009).E-mail: ancolive@gmail.com. 
O partido socialista chileno nos 20 anos de concertación: mudança organizacional, concessões programáticas e crise endógena | Augusto Neftali Corte de Oliveira

eficiente, avanços consistentes no enfrentamento à pobreza e reformas no sistema político. Os governos da Concertación apresentaram ao Chile um programa com objetivos bem definidos e, ainda que alguns compromissos tenham ficado para trás, em termos gerais o programa foi efetivamente implementado. Abstenções, desvios e adaptações das ideias inicialmente apresentadas deveram-se, via de regra, à busca pelo consenso com a oposiçáo parlamentar ou com os atores evolvidos nas questôes específicas. Outras vezes, no entanto, os próprios partidos da Concertación não foram capazes de chegar ao acordo necessário para defender inovaçóes importantes.

Em muitos sentidos, a trajetória da Concertación e de seus governos foi marcada por um processo de concessôes em dois níveis: as concessôes das forças de esquerda - especialmente de setores do Partido Socialista (PS) -, em favor da unidade e da manutençáo da coalizáo, e as concessóes do governo diante da oposição congressual e das forças econômicas e sociais influentes. Esse processo de concessóes em dois níveis, antes de ser gratuito, tanto responde à origem da coalizão quanto foi essencial para suas vitórias eleitorais. Por um lado, a busca do consenso está no cerne da fundação da Concertación, no que constitui sua identidade em oposição à intransigência da ditadura Pinochet e aos conflitos que dividiram o país no tempo do governo Allende. Por outro, as concessóes sempre foram justificadas perante os setores de esquerda do Chile atual por permitirem que se mantivesse ativo o projeto de poder da coalizão.

Negociaçôes, barganhas e acordos definiram não apenas os rumos programáticos da Concertación, mas também estiveram presentes em suas disputas internas, na definição das listas aos cargos parlamentares, na composição dos Ministérios e na definição dos candidatos presidenciais. Um efeito colateral dessa pactuação constante na vida da Concertación - em geral entabulada pelas altas lideranças nacionais - foi colocar em segundo plano a disputa política franca e direta, limitando a participação das bases dos partidos em suas decisóes e limitando as opçóes apresentadas ao eleitorado. Outro efeito relativo à política de acordos foi o enrijecimento das relaçóes entre os partidos e entre seus grupos internos, uma circunstância favorecida pelo sistema eleitoral binominal ${ }^{2}$.

2 Existem 60 distritos de magnitude dois para a eleição de deputados, tendo o eleitor um voto. Cada partido ou pacto pode apresentar uma lista binominal por distrito. Elegem-se ambos caso a soma de seus votos seja maior do que o dobro da segunda lista. Caso contrário, elege-se o primeiro de cada uma. As mesmas regras se aplicam aos 19 distritos senatoriais. 
O presente artigo apresenta essas características da política chilena com foco na atuação do Partido Socialista. A análise centra-se no processo de mudança partidária, buscando compreender as relaçóes entre a organizaçáo interna da agremiaçáo e seus objetivos ideológicos no contexto das interaçóes no ambiente político e, mais especificamente, eleitoral. Por meio do estudo dos programas de governo da Concertación e das ideias internas do PS, indica elementos que apontam para as concessôes realizadas pelo partido, em especial por seus setores de esquerda, e como essas concessóes estão implicadas dentro do projeto de poder da coalizão e do próprio PS. Ademais, apresenta as circunstâncias nas quais esse sistema alcançou sua exaustáo.

\section{A fundação do Partido Socialista e da Concertación}

Os partidos políticos desempenharam um papel relevante e precoce na construção das instituiçôes políticas do Chile. Valenzuela $(1985,1995)$ observa que a democracia chilena tem suas bases na reforma eleitoral de 1874, a qual permitiu o desenvolvimento de partidos ligados aos interesses dos operários, a ascensão de um sistema partidário que contemplou todas as correntes políticas relevantes e a instituição de eleiçôes verdadeiramente competitivas. Após um momento de instabilidade e repressão política, em 1933 quatro agremiaçóes de esquerda uniram-se para fundar o Partido Socialista (WITKER, 1993, p. 16).

Com a reestruturação dos sindicatos, e tendo a possibilidade de agregar um amplo espectro das forças de esquerda, o PS tornou-se um ator político relevante do período democrático que se estendeu de 1933 até 1973 (VALENZUELA, 1995, p. 36). Inclusive, parte do PS participou dos governos liderados pelos radicais entre 1938 e 1952. Nas eleiçóes de 1970 o partido formou com radicais e comunistas a Unidade Popular e conquistou a presidência do Chile para o socialista Salvador Allende, com 36,3\% do sufrágio. Durante seu governo, foram adotadas fortes iniciativas redistributivas e de intervenção na economia que, conforme Loveman (2001, p. 250, 259), somaram-se ao lockout de empresários e ao boicote dos bancos internacionais para dar origem a uma séria crise econômica. No campo político, o setor de esquerda manteve a mobilizaçáo para que o governo adotasse reformas mais profundas. A oposição, em seu turno, falhou ao tentar obter a maioria necessária nas eleiçóes parlamentares de março de 1973 para promover o 
O partido socialista chileno nos 20 anos de concertación: mudança organizacional, concessões programáticas e crise endógena | Augusto Neftali Corte de Oliveira

impeachment do presidente - o apoio a Allende havia subido para $44 \%$ dos votos (SILVA, 2002, p. 253).

O golpe militar de setembro de 1973 interrompeu a democracia no Chile. O regime autoritário fechou o Congresso, baniu todos os partidos políticos, realizou expurgos no governo e nas universidades e iniciou as perseguiçóes e os assassinatos que marcaram com terror o período. O PS atravessou a ditadura de Pinochet organizado no exílio e na clandestinidade. Roberts (1994) salienta que a difícil manutenção do PS naquele período foi facilitada pelas características organizacionais desenvolvidas pela agremiação, especialmente a falta de centralidade e hierarquia, proveniente de sua formação a partir de grupos preexistentes, a influência de caudilhismos locais, a preponderância de seccionais como organizaçôes de base (e não células), a militância voluntária de tempo parcial e as diferentes facçóes ideológicas.

Assim, conforme o autor, durante os tempos de exceçáo o PS ativou três mecanismos de adaptação: penetração ideológica, a capacidade de interagir com ideias e acontecimentos exógenos e então mudar suas posiçóes; absorção ideológica, a capacidade de incorporar novas e diferentes forças políticas; e inovação endógena, a capacidade de rever o curso de sua atuação a partir do pluralismo e da divergência de seus grupos internos (ROBERTS, 1994, p. 24-26). Em 1979 os líderes exilados do PS dividiram o partido em duas principais correntes, uma liderada por Carlos Altamirano e outra por Clodomiro Almeyda, que reagiram de maneira diferente aos acontecimentos da cena chilena e mundial.

O PS-Altamirano, operando a partir da Europa ocidental (Itália e França), recebeu o impacto dos partidos eurocomunistas e social-democratas, promoveu a revisão de suas ideias com as teorias de Gramsci e passou a defender a democracia como parte do avanço ao socialismo. Em face do regime militar, o PS-Altamirano iniciou a defesa de uma transição pacífica, o que permitiu o acordo com a democracia cristã na Alianza Democrática e posteriormente na Concertación de Partidos por el No. Já o PS-Almeyda operava a partir de Berlim, próximo ao bloco comunista, e contava com a maioria dos militantes do partido que permaneceram no Chile. Remanesceu com posiçôes ideológicas mais ortodoxas e aliou-se com o PCCh, que fomentava a insurgência contra o regime, no Movimiento Democrático Popular. 
No lastro da crise econômica de 1982 a oposição venceu a repressão em grandes manifestaçôes (LOVEMAN, 2001; SILVA, 2002). A repercussão negativa do atentado contra Pinochet, em 1986, e a vitória do "não" no plebiscito de 1989 sobre a continuidade da ditadura ${ }^{3}$ favoreceram a via de transiçáa pacífica e a mobilização em torno da abertura institucional. Mesmo assim o regime militar foi capaz de impor um conjunto de regras direcionadas a limitar a eventual vitória da oposiçáo - como o sistema eleitoral binominal para as eleiçóes congressuais, o desenho favorável dos distritos eleitorais e os senadores indicados pelas Forças Armadas e outras organizaçôes.

Durante a abertura democrática o Chile vivenciou a rápida reorganizaçáo do sistema partidário em um padráo próximo ao encontrado antes do golpe de 1973. Formaram-se dois principais partidos de direita: o conservador Renovación Nacional (RN) e o pró-livre mercado Unión Demócrata Independiente (UDI). Essas agremiaçóes apoiaram Pinochet no plebiscito de 1988 e mantiveram acordos para as eleiçóes seguintes. A direita, entretanto, não logrou a coordenação e unidade da centro-esquerda na Concertación de Partidos por el No e, depois, na Concertación de Partidos por la Democracia - formada inicialmente por dezessete partidos, sendo os principais o Partido Demócrata Cristiano (PDC), o Partido Radical (PR, depois Partido Radical Social Democrata, PRSD) e o Partido por la Democracia (PPD). Para Boeninger (2007, p. 21) a experiência chilena atual comprova a existência de um sistema partidário com longa tradição, continuidade considerável, de natureza programática e ideológica e com grande inserção na sociedade.

O PPD foi formado em 1987 como um partido instrumental, voltado para representar a esquerda na coalizão com o PDC e suprir a falta de registro oficial do PS. O PPD uniu o PS-Altamirano (renovado), socialistas cristãos, radicais e dissidentes comunistas. O PS-Almeyda (ortodoxo) aproximou-se da Concertación a partir da preponderância da via negociada na transição, do fim do regime comunista na Europa oriental e do fracasso eleitoral de sua aliança com o PCCh nas eleiçóes parlamentares de 1989. Entretanto, o PS só se reunifica em 1990 - e até 1992 permitiu a dupla militância com o PPD

3 A oposição, dividida como estava, não conseguiu controlar a transição, mas ao menos pôde garantir a lisura do plebiscito previsto pela Constituição de 1980, com o qual Pinochet pretendia legitimar o projeto de democracia protegida e continuar no poder até 1997 (SILVA, 2002, p. 457). 
O partido socialista chileno nos 20 anos de concertación: mudança organizacional, concessões programáticas e crise endógena | Augusto Neftali Corte de Oliveira

(SALCEDO; FUENTE, 2007, p. 102).

\section{O Partido Socialista no sistema político chileno (1989-2009)}

A trajetória do Partido Socialista após a redemocratização do Chile responde a três arenas de divisão de poder: (a) dentro da Concertación, na qual o PDC desempenhou o papel de fiador do apoio do centro ideológico e da classe média; (b) em sua relação com o PPD e, posteriormente, com o PRSD, com os quais formou o bloco progressista dentro da Concertación; (c) na relação congressual de tipo consensual com os partidos de direita (RN e UDI), especialmente durante os governos dos socialistas Lagos e Bachelet. A par dessas arenas externas, ressalta-se a manutenção da importância das correntes internas do partido em seu processo de tomada de decisão (SALCEDO; FUENTE, 2007, p. 104).

Como observado, o PS formou-se a partir de pequenos grupos políticos e em diversos momentos setores internos tomaram caminhos diferentes. Após a redemocratização, as duas facçôes em que a agremiação se dividiu durante a ditadura, PS-Altamirano e PS-Almeyda, deram origem a uma série de grupos que disputam liderança, espaço político e influência programática. Gamboa e Salcedo (2009, p. 677) observam que os grupos do PS não desenvolvem uma estrutura autônoma, não possuem sedes ou recursos próprios. Caracterizam-se, conforme os autores, como redes estáveis de militantes em torno de lideranças que compartilham visóes estratégicas e buscam assegurar uma posição de poder dentro do partido.

Em relação ao campo de esquerda extra-Concertación, sobretudo ao PCCh, Huneeus (2005, p. 83) aponta que um efeito do sistema binominal protege a posição do PS: o voto útil torna difícil o avanço eleitoral de uma segunda força de esquerda. Entretanto, mesmo com os chamados pactos de omissão firmados entre PS e PCCh nas eleiçôes de 2001 e no pleito local de 2008, os comunistas não melhoraram seu desempenho (PACTO..., 2001; CONSERTACIÓN E PC..., 2008). Apenas nas eleiçóes de 2009, quando compôs a lista com a Concertación, o PCCh conseguiu eleger três deputados federais. Nos pactos de omissão, uma agremiação deixa de apresentar candidato em certos distritos, defendendo o candidato da outra, em troca de igual favorecimento em outro distrito. Nota-se, portanto, que a política de acordos 
alcança o ambiente externo à Concertación.

A relação entre os partidos na Concertación não é isenta de conflitos. Foram comuns acirramentos sobre as políticas públicas - ao ponto de iniciativas do governo serem obstruídas -, sobre a escolha dos candidatos e as indicações para cargos públicos. Altman (2008, p. 243) aponta que o processo de escolha do candidato presidencial da Concertación tornou-se gradualmente mais democrático entre 1989 e 1999 . Ademais, o autor salienta que o partido que perde a indicação para presidente é compensado, via política de acordos, na indicação dos candidatos parlamentares. Mesmo com a resolução por primárias em 1993 e 1999, essa tendência de democratização parece ter sido superada pela política de acordos em 2005 e 2009. Em 2005 a pré-candidata do PDC abandonou a postulação em decorrência do desempenho superior de Bachelet nas pesquisas de intenção de voto (HUNEEUS, 2007, p. 97).

Em 2009, apesar de protestos e deserçóes, o PS decidiu pelo apoio à pré-candidatura presidencial do PDC e inviabilizou a inscrição de seus membros no processo de eleiçôes primárias. Logo após a desistência do único pré-candidato socialista formalmente apoiado pelo partido (José Miguel Insulza), já se organizava um grande consenso em torno do ex-presidente democrata-cristão Eduardo Frei, unindo PDC, PS e PPD e excluindo apenas os radicais ( $\mathrm{La} \mathrm{Na}$ cion, 2009). Por fim, foram realizadas primárias entre Frei e o pré-candidato do PRSD. Devido às regras adotadas, o democrata-cristáo foi considerado vitorioso ao conquistar uma vantagem de $20 \%$ nas primeiras duas regióes em que o processo foi dividido, impedindo sua realização nas outras treze regiôes.

$\mathrm{O}$ veto a inscriçôes nas primárias e o apoio ao pré-candidato Frei foi um dos motivos que levaram Enríquez-Ominami a propor sua candidatura independente em 2009. Recém-desfiliado do PS, sua candidatura parece ter comprometido a votação da Concertación nessas eleiçóes: o candidato obteve $20 \%$ do sufrágio no primeiro turno, na maior votação de uma terceira força no novo período democrático chileno. Ao mesmo tempo, a votação de Frei (30\%) foi a mais baixa obtida pela Concertación, com uma diferença de 15 pontos percentuais para o primeiro turno das eleições anteriores (Sítio Histório Electoral, 2009).

Um momento crítico para o bloco progressista (PS, PPD e, após 2000, 
O partido socialista chileno nos 20 anos de concertación: mudança organizacional, concessões programáticas e crise endógena | Augusto Neftali Corte de Oliveira

PRSD) é o da definição dos candidatos parlamentares, o que ocorre após intensa barganha entre as agremiaçôes (NAVIA, 2008). Usualmente, o bloco apresenta um dos dois nomes da lista da Concertación em cada distrito, cabendo o outro ao PDC. Não obstante, essa divisão entre os blocos deixou de ser clara nas últimas eleiçóes. A primeira exceção ocorreu em 2005, quando a disputa interna do PS inviabilizou o acordo em um distrito, levando o PDC a retirar seu candidato em favor do PPD. Nas eleiçóes locais de 2008 foram organizadas duas listas da Concertación, uma unindo PPD e PRSD e outra PDC e PS. As eleiçóes gerais de 2009 criaram uma situação nova, na qual a Concertación lançou lista conjunta com o pacto do PCCh. Os distritos senatoriais mantiveram o padrão, mas nos de deputados o PS concorreu contra PPD e PRSD em 10 casos e com o PCCh em um (tendo apresentado candidatos em 23 dos 60 distritos) (Biblioteca del Congreso Nacional de Chile, 2009).

Assim, por força das regras instituídas no sistema binominal, a definição dos postulantes - armar a lista - passa por intensa negociaçáo entre as agremiaçóes que compóem a Concertación e até mesmo com outros partidos. Sobre o tema, Aninat e outros (2004, p. 18) destacam que as regras formais das eleiçôes chilenas forçam os partidos a firmar acordos viáveis dentro de suas coligações, o que favorece a disciplina na coligação, o poder das lideranças partidárias e a disciplina partidária. Os líderes partidários e das coalizões são fortalecidos exatamente por deterem o controle sobre a definiçáo das candidaturas, podendo punir os aspirantes que faltam com lealdade ao partido e recompensar os que seguem as prescriçóes.

Além disso, Navia (2008, p. 105) destaca que, via de regra, quem consegue formar um nome forte o suficiente para pleitear uma nova indicação à candidatura parlamentar são aqueles que, ocupando cargos no governo, criam fortes relaçốes com os eleitores em seus distritos. Ao lado da lealdade ao governo, Marenco e Serna (2007, p. 104) mostram que os parlamentares do PS possuem elevado tempo de filiação partidária, o que indica uma seleção de candidatos que valoriza a lealdade com o partido.

O quadro a seguir apresenta o número de cadeiras parlamentares conquistadas pelo PS na democracia recente. A discrepância entre o percentual de votos e o número de cadeiras obtidas nas sucessivas eleiçôes pode ser um indicativo da relevância de uma lista armada favoravelmente ao partido no sistema binominal chileno. 


\begin{tabular}{|lc|c|c|c|c|c|c|}
\cline { 2 - 7 } \multicolumn{1}{c|}{} & $\mathbf{1 9 8 9}$ & $\mathbf{1 9 9 3}$ & $\mathbf{1 9 9 7}$ & $\mathbf{2 0 0 1}$ & $\mathbf{2 0 0 5}$ & $\mathbf{2 0 0 9}$ & Em disputa \\
\hline Deputados & 7 & $\begin{array}{c}15 \\
(11,9 \%)\end{array}$ & $11(11,1 \%)$ & $10(10,0 \%)$ & $\begin{array}{c}15 \\
(10,1 \%)\end{array}$ & $11(9,9 \%)$ & 120 \\
\hline Senadores & 1 & $3(10,6 \%)$ & $1(8,1 \%)$ & $4(10,2 \%)$ & $8(21 \%)$ & $5(13,1 \%)$ & 20 \\
\hline
\end{tabular}

Elaboração do autor. Entre parênteses a percentagem de votos do PS sobre o total. Dados do Ministério do Interior (Sítio Histórico Electoral, 2009). Para 1989, considerado após unificação do PS (eleitos pelo PPD e PAIS). Cargos "em disputa” conforme números de 2009.

\section{Quadro I. Deputados e Senadores eleitos pelo PS (1989-2009)}

A literatura destaca que as agremiaçóes chilenas possuem elevado nível de coesão e disciplina no Congresso. A importância dos partidos se faz presente ainda na unidade de atuação parlamentar, na qual a reputação e a coesão ideológica das agremiaçóes superam incentivos do sistema eleitoral, que tendem a contrapor os candidatos da mesma coalizáo em cada distrito (dada a expectativa de que apenas o mais votado em cada lista se elegerá) (MORGENSTERN, 2002, p. 427). Alemán e Saiegh (2007) sustentam que o sistema partidário parlamentar se estrutura à imagem das alianças, com uma dinâmica dual (esquerda - direita), embora o sistema partidário tenda a se organizar em três grupos (esquerda - centro - direita), como no período anterior a golpe de 1973. Trata-se possivelmente do impacto do sistema eleitoral, somado à organização da Concertación após o plebiscito de 1988.

Como destacado, é sobretudo no Congresso que o PS interage com os partidos de direita (RN e UDI). Em que pese o presidente chileno possuir elevados poderes de agenda, as gestóes da Concertación mantiveram uma democracia consensual, com abertura de espaço para o diálogo com a oposição e cooperação com o Congresso (SIAVELIS, 2003; HUNEEUS, 2005). Com outra interpretação a respeito da causa dessa democracia consensual, Garretón (2003) sustenta que a representaçáo sobredimensionada da direita por meio do sistema binominal (que favorece a segunda força), em conjunto com as maiorias especiais exigidas para emendar a Constituição, confere um poder de veto à minoria e enfraquece o poder do presidente. Conduz, portanto, à exigência de acordos com a oposição para passar matérias relevantes pelo Congresso.

De fato, durante os governos Lagos e Bachelet a negociação com a oposição e a busca de consensos (em especial com a $\mathrm{RN}$ ) continuaram sendo 
O partido socialista chileno nos 20 anos de concertación: mudança organizacional, concessões programáticas e crise endógena | Augusto Neftali Corte de Oliveira

necessárias, em especial em questôes que exigiram quóruns qualificados, como alteraçôes nas instituições políticas e regulamentação de políticas sociais. Foi o caso, por exemplo, da aprovação do Seguro Desemprego no início do governo Lagos, quando os votos da RN supriram deserçóes de parlamentares do PDC (OPOSICIÓN..., 2001).

Outro momento politicamente relevante encontra-se nas eleições de conselheiros municipais e alcaides, sendo que mesmo nesse nível a política de acordos está presente. Entre 1992 e 2008 o PS conquistou os cargos locais conforme o quadro a seguir. Note-se que em 2008 a Concertación apresentou listas separadas: Democrática (PDC e PS) e Progressista (PPD e PRSD). Essa circunstância pode indicar uma açáo do PS em favor do PDC e da Concertación, talvez orientada para a estabilidade política na segunda metade do governo Bachelet.

\begin{tabular}{|l|c|c|c|c|c|c|}
\cline { 2 - 7 } \multicolumn{1}{c|}{} & $\mathbf{1 9 9 2}$ & $\mathbf{1 9 9 6}$ & $\mathbf{2 0 0 0}$ & $\mathbf{2 0 0 4}$ & $\mathbf{2 0 0 8}$ & Em disputa \\
\hline Alcaides & 35 & 38 & 32 & $45(11,8 \%)$ & $29(9,3 \%)$ & 345 \\
\hline Conselheiros & $174(8,5 \%)$ & $208(10,7 \%)$ & $239(11,3 \%)$ & $255(10,9 \%)$ & $250(11,1 \%)$ & 2.130 \\
\hline
\end{tabular}

Elaboração do autor. Dados do Ministério do Interior (Sítio Histórico Electoral, 2009). Até 2000 os alcaides eram eleitos indiretamente pelos Conselheiros em cada município. Cargos "em disputa" conforme números de 2008.

Quadro 2. Alcaides e conselheiros eleitos pelo PS (1992-2008)

A formação do governo também cria tensão entre os partidos - embora o tema seja tratado de maneira velada e a direçáo do PS, ao menos durante os governos Lagos e Bachelet, tenha defendido a prerrogativa do presidente nas nomeaçôes (PRIETO, 2001; SALINAS, 2006). Conforme Altman (2008), os governos da Concertación buscaram criar ministérios congruentes com o poder dos partidos no Parlamento e desenvolveram mecanismos de integração horizontal (cargos relevantes do ministério são ocupados por membros de partidos diferentes do do Ministro). Essas características foram observadas especialmente nos governos Aylwin e Lagos. Durante os governos Lagos e Bachelet, o PS manteve quatro ministérios sob seu controle, o que representa cerca de $20 \%$ do total de postos do gabinete (26 CONGRESO..., 2000; SCHERMAN, 2006).

Embora a participação no governo forneça vantagens objetivas, como recursos financeiros a partir de contribuição sobre remuneração de funcionários, 
divulgação pública de lideranças e influência sobre o processo de formação de políticas públicas, no caso do Chile a literatura aponta uma circunstância adversa proveniente do perfil técnico dos governos da Concertación (ANGELL, 2003, p. 104; HUNEEUS, 2005, p. 45). Os governos da Concertación primam por uma gestão administrativa e consensual, com pouco espaço para realizaçóes simbólicas e com marcada orientação pró-mercado. Assim, os partidos arcam com o ônus de fragilizar os incentivos ideológicos para sua militância e dificultar suas relaçôes com associações sociais ${ }^{4}$. Esse é um problema saliente para o PS, que possui fortes ligaçóes com sindicatos e disputa esse espaço com o PCCh. A participação nos governos pode, portanto, causar efeitos negativos sobre a unidade partidária, na medida em que atinge a reputação da legenda e prejudica sua conexáo com a base partidária e com eleitores.

A atuação do PS no sistema político do Chile depende de múltiplos arranjos, que envolvem desde seus parceiros mais próximos até os adversários ideológicos, como permitem inferir as circunstâncias que foram descritas. Essa estruturação da política chilena possui o condão de fortalecer a mediação e os acordos como mecanismo de solução de disputas, o que em boa medida regula o embate direto entre as agremiaçóes, quer no momento eleitoral, quer nas questôes concernentes ao governo. Como observado, em tais condiçôes as lideranças assumem um papel determinante na condução da vida política e deixam pouco espaço para soluçóes vindas da base dos partidos. A manutenção dos complexos acordos entre os líderes políticos, ao fim, tolhe as alternativas de mudança de curso e inovaçáo frente aos desafios apresentados aos partidos.

Considerando os mecanismos de adaptação do PS destacados por Roberts (1994), a situação da agremiação frente à rigidez da vida democrática chilena atual torna-se especialmente difícil. Os acordos para manutenção da Concertación, para dividir o espaço político com o bloco progressista e mesmo com o PCCh, e ainda, durante os governos Lagos e Bachelet, para construir pontes com os partidos de oposiçáo no Congresso, tornaram pequeno o espaço no PS para a manifestação de dissidências e surgimento de propostas alternativas.

4 Em geral se assume que a militância dos partidos possui maior interesse em valores ideológicos e políticas públicas do que seus líderes (STRØM, 1990), razão pela qual a adoção de posições moderadas nas eleições e no governo podem gerar ruídos na base dos partidos. Exemplos dessa situação no caso do Partido Socialista são apresentados na sequência. 
O partido socialista chileno nos 20 anos de concertación: mudança organizacional, concessões programáticas e crise endógena | Augusto Neftali Corte de Oliveira

Dessa maneira, se o pluralismo das forças internas do PS ainda fosse favorável aos mecanismos de inovação endógena, penetração e absorção ideológica, a organizaçâo da política chilena e as conexôes do PS na Concertación incentivam outra prática: a manutençáo da trajetória adotada inicialmente, dos acordos rígidos e da padronização das ideias.

\section{O Partido Socialista nos governos democrata-cristãos (1989-2000)}

Embora o Partido Socialista ainda não estivesse formalmente unificado, em outubro de 1989 lançou um documento que esclarece sua subscrição aos programas de governo da Concertación e ao do PAIS (Partido Amplio de Izquierda Socialista, que uniu a parte ortodoxa do PS com o PCCh) (Partido Socialista, 1989). Tal qual o programa da Concertación, o PS apresenta preocupaçóes centrais com a democracia - em afastar a tutela militar e incentivar a participaçáo popular -, mas o documento socialista não possui o enfoque consensualista, nem a mesma moderação ao abordar as transformaçóes econômicas que deseja ver implementadas. O primeiro programa de governo da Concertación de Partidos por la Democracia preocupa-se em defender a superaçáo das extremas desigualdades de renda e oportunidades, mas de maneira atrelada à competitividade da economia: "no habrá crecimiento, justicia y paz social, por un manejo inadecuado de la economía o por tratar de alcanzar metas incompatibles con los recursos efectivamente movilizables" (CONCERTACIÓN DE PARTIDOS POR LA DEMOCRACIA, 1989, p. 11). Essa é uma diferença importante entre o PS e a Concertación neste momento.

A eleição presidencial de 1989 foi vencida pelo candidato da Concertación, Patrício Aylwin. Seu governo foi marcado pela busca do consenso junto à oposição. De fato, a posição minoritária no Senado e o temor de uma nova intervenção militar pesaram contra iniciativas mais incisivas para reformar o sistema político (LOVEMAN, 2001, p. 313). No campo econômico, instaurou-se uma política altamente consensual de liberalização econômica, conforme Scully (1994, p. 10). O autor também destaca que o governo aumentou em $30 \%$ o gasto social, o que - em conjunto com o forte crescimento econômico do período - permitiu retirar da pobreza quase $20 \%$ do total de pobres.

Esses avanços, a boa aceitação do governo e a derrota do PAIS nas eleições parlamentares favoreceram a reunificação do PS e sua adesão à 
Concertación. No congresso partidário de dezembro de 1992, o PS lançou as bases programáticas da pré-candidatura do socialista Ricardo Lagos à Presidência - derrotada por Eduardo Frei Ruiz-Tagle (PDC) nas primárias de 1993. Naquele congresso, mesmo apoiando o governo, os socialistas defendem uma maior atuaçáo do Estado enquanto promotor de oportunidades sociais (Partido Socialista, 1992). Seu eixo principal é a integração dos pobres ao processo produtivo.

Ainda assim, o programa oficial da candidatura de Frei em 1994 vai muito mais longe em defesa de uma política macroeconômica rigorosa. Segundo esse programa, o crescimento econômico deve ser alcançado com baixa inflação, controle severo das finanças públicas e uma política monetária que assegure a competitividade internacional do país (CONCERTACIÓN DE PARTIDOS POR LA DEMOCRACIA, 1994, p. 45). Nesse sentido, projeta inclusive o eventual contingenciamento do gasto social. Esses são pontos claramente destoantes entre as pretensóes da Concertación e dos socialistas.

O bom desempenho da economia durante o governo Lagos, até a crise asiática de 1998, associou crescimento econômico e diminuição da pobreza, embora sem grandes avanços contra a desigualdade social (FFRENCH-DAVIS; GOMÁ, 2003). A política social que mais recebeu atenção do governo foi a educação, em especial por meio de incentivos dirigidos de maneira focalizada aos estabelecimentos municipais e privados subvencionados nas áreas mais carentes (GAJARDO, 2003).

Ao comparar as ideias defendidas pelo PS e pela Concertación no período liderado pelos democrata-cristáos, nota-se que a agremiação precisou colocar de lado suas posições favoráveis à ação direta do Estado, especialmente nas políticas sociais. Alguns fatores contribuíram para que essas divergências não gerassem um conflito maior. A Concertación assumiu o governo com o gasto público defasado, os serviços estatais precisavam ser recuperados. Como já indicado, embora não com a presteza desejada pelos socialistas, o governo avançou nesse sentido. Além disso, lideranças do setor centrista da coalizão (PDC) e do setor socialista reformado (PPD e parte do PS) já assumiram o governo com uma interpretaçáo positiva sobre os ajustes econômicos promovidos no governo Pinochet (FOXLEY, 1990). Por fim, durante o período houve temor a respeito do recrudescimento militar, o que, em conjunto com a vigilância da oposição no Congresso, pode ter favorecido a moderação nas exigências dos setores de esquerda do PS. 
O partido socialista chileno nos 20 anos de concertación: mudança organizacional, concessões programáticas e crise endógena | Augusto Neftali Corte de Oliveira

\section{O Partido Socialista no governo Lagos (2000-2006)}

Em seu congresso de maio de 1998, o PS aprovou um balanço dos governos da Concertación e uma proposta de programa para Ricardo Lagos, novamente pré-candidato à Presidência. As resoluçôes ressaltam que a Concertación conseguiu restabelecer o governo democrático e as liberdades civis, além de importantes avanços no campo econômico e social. Ainda assim, o documento dá um passo firme em direção a cobranças mais incisivas nas políticas sociais e no combate à desigualdade. Buscando atacar as razóes pelas quais não foram realizados maiores avanços, o PS propóe que a política de consensos entre os altos escalóes políticos deve dar lugar ao poder real da maioria (embora não explicitamente, essa ideia remete a um slogan do tempo de Allende). A proposta do PS novamente é mais incisiva quanto ao papel do Estado:

Nós, socialistas, afirmamos que sem um Estado vigoroso não haverá igualdade de oportunidades, nem tampouco um desenvolvimento integral e sustentável. Rechaçamos a ideia de um Estado mínimo ou subsidiário. É necessário um Estado democrático que assegure a governabilidade do processo de mudanças e a inserção internacional do Chile. Um Estado que abra oportunidades para todas as pessoas, que garanta o acesso de todos os chilenos aos bens públicos e que assegure direitos cidadãos. Um Estado que tenha força reguladora para garantir uma concorrência justa. Um Estado que guie o desenvolvimento nacional com uma estratégia de longo prazo orientada para aumentar a qualidade de vida de todos os chilenos $^{5}$. (PARTIDO SOCIALISTA, 1998, tradução nossa).

A primária de 1999, em que Lagos venceu o pré-candidato do PDC, marcou o ingresso do PRSD no bloco progressista com PS e PPD. O programa de governo da candidatura Lagos destacou as principais ideias já presentes na fundação da Concertación, de crescimento econômico com diminuição da desigualdade social. Em uma aproximação com o programa dos socialistas, enfatiza a necessidade de reorientar o Estado para servir aos mais necessitados - com destaque para a questão da saúde. A interpretação sobre a relação entre

5 No original: "Los socialistas afirmamos que sin un Estado vigoroso no habrá igualdad de oportunidades, ni tampoco un desarrollo integral y sustentable. Rechazamos la idea de un Estado mínimo o subsidiario. Se requiere un Estado democrático que asegure la gobernabilidad del proceso de cambios y la inserción internacional de Chile. Un Estado que abra las oportunidades para todas las personas, que garantice el acceso de todos los chilenos a los bienes públicos y que asegure derechos ciudadanos. Un Estado que tenga fuerza reguladora para garantizar una justa competencia. Un Estado que oriente el desarrollo nacional con una estrategia de largo plazo orientada a elevar la calidad de vida de todos los chilenos". 
Estado e mercado aparece nítida na apresentação do texto: "[...] a igualdade não pode ser criada artificalmente pelo Estado. Mas tampouco nasce automaticamente do mercado" (CONCERTACIÓN DE PARTIDOS POR LA DEMOCRACIA, 1999, p. 4, tradução nossa). As diretrizes da política econômica são sucintas e incisivas: controle da inflação, autonomia do Banco Central, disciplina fiscal, melhora da eficácia do gasto público. Em suma, cumprir com os compromissos sociais sem pôr em risco o crescimento e a estabilidade econômica. Não cede, portanto, ao apelo do PS em torno de um Estado forte.

Ainda sob os reflexos da crise asiática, nos primeiros anos do governo Lagos não houve crescimento econômico. Para Fazio e Prada (2006, p. 23), o conservadorismo da política macroeconômica falhou em produzir efeitos anticíclicos. No campo político, por outro lado, foram derrogados os entraves autoritários mais evidentes, inclusive os senadores designados e vitalícios. Essas medidas, e também as inovaçôes no campo das políticas sociais, como o seguro-desemprego e o Chile Solidario, precisaram ser negociadas com a oposição na busca de consensos. Mesmo com a primeira proposta mais favorável ao setor estatal vetada no Congresso, a reforma da saúde pública com o Plano Auge - honrou o compromisso prioritário da candidatura Lagos (BOENINGER, 2008, p. 161).

Angel e Pollack (2000, p. 375) salientam que os mandatos presidenciais democrata-cristãos responsabilizaram-se por consolidar a transição democrática e a modernização do Estado, mas Lagos foi eleito em meio a elevadas expectativas sobre a redução da pobreza e da desigualdade social. A manutenção da política de consensos e o conservadorismo demonstrado no início do governo Lagos, no campo econômico e social, frustraram as expectativas demonstradas pelos socialistas em seus documentos. Essa situação instaura uma crise entre o PS e o governo, com importantes desdobramentos na organização interna da agremiação.

Já no primeiro ano de governo, Ricardo Nunes, presidente do PS e líder do setor renovado, apresenta a posição crítica do partido sobre a atuação de Lagos: “[...] deve-se escutar os empresários e o capital, mas não em prejuízo

6 No original: "[...] la igualdad no puede ser creada artificialmente por el Estado. Pero tampoco nace automáticamente del mercado". 
O partido socialista chileno nos 20 anos de concertación: mudança organizacional, concessões programáticas e crise endógena | Augusto Neftali Corte de Oliveira

dos trabalhadores e de quem vive de um salário"7 (CONCERTACIÓN DE PARTIDOS POR LA DEMOCRACIA, 1999, p. 4, tradução nossa). Na eleição interna de maio de 2001 o comitê central socialista ratifica o embate com o governo ao eleger Camilo Escalona, deputado da corrente ortodoxa Nueva Izquierda e identificado pelas posiçóes contundentes. Em suas palavras:

Na Concertación prevalecem duas visões estratégicas para compreender o país e a ação do governo. Uma está na origem da Concertación e aspira recuperar a democracia e realizar a justiça social. Outra se desenvolveu nos últimos anos, sua raiz está no liberalismo econômico, mas é claramente de cunho neoconservador. Esta visão pretende resolver os problemas do país cuidando dos ricos, como disse Pinochet em sua época, ou seja, privatizando o pouco que resta em mãos públicas, debilitando ainda mais o setor estatal e apostando todo o futuro do país nas leis do mercado. (PS CRITICÓ..., 2000, tradução nossa).

Ao longo de sua administração, Lagos compromete-se com alguns pontos das demandas dos socialistas - direcionadas para o aumento do gasto social e das pensôes previdenciárias, ou para o fortalecimento do papel do Estado nas políticas sociais. Por outro lado, o presidente Lagos passou a cobrar esforços dos ministros socialistas, especialmente do influente ministro do Interior, José Miguel Insulza, no sentido de colocar ordem no partido (GARRIDO; GUERRA, 2002). De qualquer forma, os principais líderes do partido efetivamente abaixam o tom do discurso. Ao assumir a presidência socialista em 2001, Escalona apresenta-se mais moderado: o PS será leal ao presidente Lagos, mas “[...] isso não significa a incondicionalidade irracional de quem não pensa, senão a lealdade de quem tem um projeto político, uma visáo de país e um compromisso com o mundo popular" (SOCIALISMO..., 2001, tradução nossa).

Mesmo após os escândalos de corrupção de 2002, que levaram a Concertación a turbulências maiores, e perante as posiçôes duras do PDC, os líderes

7 No original: "[...] hay que escuchar a los empresarios y al capital, pero no en desmedro de los trabajadores y de quienes viven de un sueldo y un salario".

8 No original: "En la Concertación prevalecen dos visiones estratégicas para comprender el país y la acción de gobierno. Una está en el origen de la Concertación y aspiraba a recuperar la democracia y lograr la justicia social. La otra se ha desarrollado en los últimos años, su raiz está en el liberalismo económico pero es claramente de cuño neoconservador. Esta visión pretende resolver los problemas del país cuidando a los ricos, como dijo Pinochet en su época, es decir privatizando lo poco que queda en manos públicas, debilitando aún más el sector estatal y apostando todo el futuro del país a las leyes del mercado".

9 No original: "eso no significa la incondicionalidad irracional de quienes no piensan, sino la lealtad de quienes tienen un proyecto político, una visión de país y un compromiso con el mundo popular". 
do PS e PPD uniram-se em defesa do governo. Não obstante, a insatisfação entre os setores sociais do partido não arrefeceu, como revela a declaraçáo do entâo presidente da Central Unitaria de Trabajadores (CUT), Arturo Martínez, membro do PS:

Mas como se sente com o PS atual? "Não muito cômodo porque o PS nasceu para se opor a um sistema, a um modelo, e estamos administrando um modelo neoliberal que não nos leva ao socialismo, portanto estamos fazendo ao contrário. O PS passou para o lado da social-democracia. Já não planeja a construção do socialismo senão que as pessoas vivam melhor. Acomodou-se"'10. (LEVINSKY, 2003, tradução nossa).

As disputas internas seguintes não deram espaço para críticas contundentes ao governo. Em 2003 venceu Gonzalo Martner, até então ministro da Secretaria Geral da Presidência. Em 2005, quando o governo Lagos logrou aumentar sua aprovação entre a população e Bachelet já despontava como presidenciável, as grandes tendências dos setores renovado e ortodoxo do PS uniram-se em defesa de uma candidatura em oposição ao dirigente Martner. O membro de uma corrente menor criticou essa disputa dizendo que os que teciam as críticas, tanto quanto os criticados, pareciam ser partes do mesmo processo de privatização da política e oligarquizaçáo do poder que transformou os partidos em máquinas de poder, sem ideias nem programa (AHUMADA, 2005).

Essa configuração de forças, com a coalizão de setores então antagônicos e a ampla preponderância da posição pró-governo, favoreceu a adesão plena do PS ao projeto da Concertación. Fechou-se, assim, o movimento iniciado pelos socialistas ainda na redemocratização.

Ao lado da mudança na conformação do PS, outras inovaçóes possuíram impacto organizacional, por alterar os recursos financeiros disponíveis para a agremiação: a partir de 2002 o governo passou a pagar uma indenização pelo confisco dos bens dos partidos durante o regime militar e, em 2003, foi aprovado o financiamento público parcial das campanhas eleitorais. Embora as fontes privadas continuem relevantes, esses recursos permitiram ao os,

10 No original: "Pero cómo se siente con el actual PS? 'No muy cómodo porque el PS nace para tratar de oponerse a un sistema, a un modelo, y estamos administrando un modelo neoliberal que no nos lleva al socialismo, por lo tanto lo estamos haciendo al revés. El PS ha ido pasando a la socialdemocracia. Ya no se plantea la construcción del socialismo sino que la gente viva mejor. Se ha ido acomodando"'. 
O partido socialista chileno nos 20 anos de concertación: mudança organizacional, concessões programáticas e crise endógena | Augusto Neftali Corte de Oliveira

pela primeira vez, realizar aportes às candidaturas parlamentares (SALCEDO; FUENTE, 2007, p. 115). Essas inovaçóes podem ter favorecido o movimento, já percebido por Huneeus (1998), de diminuição da importância do papel da militância para os partidos - o socialista inclusive. Uma mudança organizacional desse tipo é compatível com o enfraquecimento do discurso ideológico por parte das lideranças partidárias, como se observará na sequência.

\section{O Partido Socialista no governo Bachelet (2006-20 I0)}

Embora o presidente Lagos tenha criado laços com o PS renovado desde o exílio (SALINAS, 2000), sua liderança no processo de redemocratização e sua ligação com o PPD garantiam certa independência em relação aos socialistas. Bachelet, mesmo que tenha se tornado conhecida principalmente como ministra nas pastas da Saúde e Defesa, desenvolveu vínculos partidários mais consistentes com o PS, em especial com o setor ortodoxo (Nueva Izquierda). Mais do que com Lagos, portanto, a candidatura de Bachelet apresentou-se como um caminho viável para o projeto de poder do PS - um passo importante para o quinto partido em densidade eleitoral e no Parlamento. $\mathrm{O}$ "fenômeno Bachelet" foi sustentando pelo crescimento perene da candidata nas pesquisas de intençóes de voto: de $1 \%$ em julho de 2002, para o topo de 47\% em julho de 2005 (GAMBOA, 2007, p. 61). Pode-se inferir, portanto, sobre a existência de incentivos relevantes para que os líderes socialistas fortalecessem a conexão da agremiação com a Concertación como estratégia para a conquista da Presidência.

Essa aproximação pode ser observada por meio da consonância das propostas internas do PS com o programa da Concertación para as eleiçóes de 2006 - suprimindo as maiores diferenças reparadas nos casos de 1989, 1994 e 2000 (OLIVEIRA, 2009, p. 46). Em 2005 o PS reformula o clássico apelo de formação de uma ampla maioria, mas em direção à classe média. Afirma, por exemplo, que muitas famílias trabalhadoras, inclusive amplos segmentos da classe média, vivem na incerteza e desprotegidos frente aos riscos sociais (Partido Socialista, 2005, p. 4). O PS também diminui a exigência por um Estado mais presente nas políticas sociais. No mesmo sentido, o programa de governo da Concertación volta-se para a reduçáo da insegurança econômica não só dos mais pobres, mas também da classe média, ao mesmo tempo em que mantém o compromisso com a estabilidade econômica (CONCERTACIÓN DE PARTIDOS POR LA DEMOCRACIA, 2005). 
Vitoriosa nas eleiçôes de 2005, Bachelet manteve em seu governo a tendência já presente com Lagos. Adotou aumentos parcimoniosos na participação do Estado nas políticas sociais, efetivamente ampliando os recursos destinados aos serviços de saúde, educação e proteção social, mas sem rupturas em favor das capacidades estatais de intervir na economia ou na criaçáo e proteção de empregos (OLIVEIRA, 2009; SEHNBRUCH e SIAVELIS, 2009). A manutençáo do consenso sobre metas e práticas na tese de crescimento com equidade continuou informando, no governo Bachelet, as principais controvérsias entre os socialistas. Nas eleiçôes internas de 2008, a coalizão liderada por Escalona manteve-se na direçáo do PS, vencendo grupos opositores à direção partidária e ao governo. Mostrar as diferenças entre a coalizão dominante e esses setores minoritários ajuda a compreender os desdobramentos no interior do partido durante o mandato de Bachelet.

A Grandes Alamedas, liderada por Isabel Allende Bussi, conjuga forças renovadas e ortodoxas. Em seu manifesto, ao mesmo tempo em que critica a racionalidade tecnocrática neoliberal que impede maiores avanço sociais, defende o empenho da Concertación em "[...] assegurar e expandir liberdades, proporcionar estabilidade, paz e progresso, [...] para construir as bases de um sistema de proteção social [...] sem renunciar da necessidade do rigor fiscal ou ameaçando os equilíbrios macroeconômicos"11 (Grandes Alamedas, 2008, p. 2, tradução nossa).

Com posiçóes mais duras, os defensores do documento El Partido Socialista como Fuerza Popular afirmam que "[...] o modelo econômico-social enfraqueceu e desprotegeu os trabalhadores, os consumidores e os pequenos empresários, deixando a critério do grande capital o controle, a administração e a manipulação do mercado" ${ }^{2}$ (ARRATE, 2007, p. 1). Para este setor, o governo Bachelet, ao manter as bases da política social anterior, fortaleceu o modelo neoliberal que divide os chilenos segundo suas origens sociais. Mesmo que o discurso dessa lista seja muito mais firme em oposição às forças do mercado,

I I No original: "[...] asegurar y expandir libertades, en brindar estabilidad, paz y progreso, [...] en construir las bases de un sistema de protección social [...] sin abjurar de la necesidad del rigor fiscal o amenazando los equilibrios macroeconómicos".

12 No original: "[...] el modelo económico-social ha debilitado y desprotegido a los trabajadores, a los consumidores y a los pequeños empresarios, dejando al arbitrio del gran capital el control, administración y manipulación del mercado". 
O partido socialista chileno nos 20 anos de concertación: mudança organizacional, concessões programáticas e crise endógena | Augusto Neftali Corte de Oliveira

as duas listas apresentam críticas que correspondem àquelas que o PS dirigia à Concertación anteriormente. Por exemplo, as duas defendem a alteraçáo da política de subvenção do ensino particular em favor de escolas públicas.

Em que pesem as posiçóes das correntes minoritárias, as resoluçóes do congresso socialista de 2008 iniciam por ratificar a condição de partido de governo do PS e manifestar seu apoio irrestrito ao governo da Presidente Michelle Bachelet (Partido Socialista, 2008, p. 2). As críticas lançadas não ganharam espaço significativo. Ao lado dessa firme aliança com o governo, o PS também buscou fortalecer as relaçôes com a Concertación na divisão do poder. Nas eleiçóes locais de 2008 o PS aliou-se ao PDC, o que custou aos socialistas a perda de espaço (conforme Quadro 2). Ainda mais relevante, pela primeira vez o PS optou por apoiar o pré-candidato do PDC para as eleiçóes presidenciais de 2009. Não só o PS indicou Eduardo Frei à presidência, como vetou a inscrição de seus filiados na realização de uma eventual primária e advertiu que poderia ser negada vaga nas listas de deputados e senadores aos postulantes que apoiassem outra candidatura presidencial (CABELLO, 2009).

O entrelaçamento com a Concertación, já claro no que se refere às ideias programáticas, agora passa a medidas concretas de contenção das forças internas da agremiação em defesa da divisão de espaço político com os partidos aliados, especialmente o PDC. A política de acordos de cúpula atingiu, em 2009, um espaço até então mantido em competição aberta entre as forças da Concertación - a escolha do candidato presidencial. A ameaça de negar vaga na lista para o senador ou deputado que divergisse do apoio ao pré-candidato do PDC demonstra que a direçáo do PS estava disposta a garantir a disciplina partidária com base na ameaça de punição. Mesmo no caso dos cargos parlamentares, embora o estatuto preveja a participação da base socialista, a definição dos distritos e indicação dos candidatos manteve-se adstrita aos acordos entre as correntes internas e os parceiros do bloco progressista.

A falta de abertura para reformular as ideias do partido ou para definir o futuro candidato presidencial conduziu a um movimento de evasáo do partido. Em novembro de 2008 o senador Alejando Navarro, acompanhado de 120 militantes e seis membros do comitê central socialista, aderiu ao Partido Movimiento Amplio Social (MAS) (EL SENADOR..., 2008). O líder histórico Jorge Arrate, visando a candidatura presidencial, em janeiro de 2009 filiou-se ao PCCh. Em junho de 2009, com sua candidatura presidencial já 
lançada e apoiada pelo MAS, foi a vez de Enríquez-Ominami deixar o PS, ocasiâo em que declarou:

Mais de 20 anos após o retorno da democracia, nada justifica a manutenção dos acordos assinados em um contexto político, econômico e social muito diferente. Nada, exceto a manutenção de certos privilégios e vantagens de um pequeno grupo de dirigentes, explica o conluio e a privatização da política e seu efeito mais perverso: a concentração do poder simbólico, político e econômico em um punhado reduzido de personagens ${ }^{13}$. (TORREALBA, 2009, tradução nossa).

Considerando a mudança no PS operada durante o governo Lagos, pode-se inferir que essa nova situação deixou descoberto um campo programático de crítica progressista à Concertación, sem espaço no interior da aliança e não preenchido pelo PCCh. Como destaca Oliveira (2011, p. 218), tanto o PS quanto seu parceiro PPD mantiveram um discurso programático ideologicamente coerente, mas com baixa adesáo aos temas tradicionalmente mobilizados pelos movimentos de esquerda. Dois candidatos a presidente, Arrate e Enríquez-Ominami, assinavam o manifesto da esquerda no PS em 2008. Representantes desse setor nas eleiçóes presidenciais de 2009, eles receberam em conjunto $26,35 \%$ dos votos no primeiro turno. O candidato da Concertación alcançou 29,6\% dos votos e Sebastián Piñera (RN, UDI), 44,06\% (SÍTIO HISTÓRIO ELECTORAL, 2009).

Tal resultado apresenta uma configuração das forças políticas nos contornos do período anterior ao golpe de 1973 (esquerda - centro - direita), diferente da dinâmica dualista inaugurada no plebiscito de $1988^{14}$. A vitória de Pińera no segundo turno das eleiçôes presidenciais marcou o fim do longo ciclo de poder da Concertación. Esse fato repercutiu em todas as agremiações da coalizão. Escalona, que da presidência do PS sustentou publicamente as posiçóes mais rígidas em torno da candidatura Frei, acabou obrigado a deixar o cargo.

13 No original: "A más de 20 años del retorno de la democracia, nada justifica la mantención de los acuerdos suscritos en un contexto político, económico y social muy diferente. Nada, excepto la mantención de ciertos privilegios y réditos de un grupo pequeño de dirigentes, explica la colusión y privatización de la política y su efecto más perverso: la concentración del poder simbólico, político y económico en un reducido puñado de personajes".

14 No entanto, o campo mais à esquerda permanece com baixa representatividade no Parlamento. A coalizão que apoiou a candidatura presidencial de Enríquez-Ominami não elegeu representantes e o PCCh, de Arrate, elegeu os três primeiros deputados desde a redemocratização, em lista conjunta com a Concertación (SíTIO HISTÓRIO ELECTORAL, 2009). 
O partido socialista chileno nos 20 anos de concertación: mudança organizacional, concessões programáticas e crise endógena | Augusto Neftali Corte de Oliveira

\section{Organização, objetivos e mudanças no Partido Socialista}

A trajetória do PS após a redemocratização responde aos objetivos de poder do partido, aos constrangimentos da arena eleitoral e suas relaçóes com os outros atores partidários. Durante o período, a extensão da aliança formada pelo PS restringiu-se ao campo de centro representado pelo PDC, mas em termos programáticos exigiu a distensão em direção a políticas sociais ajustadas com as forças do mercado - com menor capacidade autônoma do Estado e efeitos redistributivos mais graduais do que o partido defendia inicialmente. A julgar pelos resultados eleitorais favoráveis obtidos pela Concertación, esse sacrifício programático foi capaz de consolidar uma ponte entre amplos setores sociais da população chilena.

Sobre a mudança ideológica do PS, observou-se a continuidade, em todo o período, de uma preocupação saliente com a promoção de condições para a igualdade social. Não obstante, a mudança na forma de atingir esse objetivo da defesa de um Estado forte para a política de crescimento econômico com igualdade social - apresenta uma limitação substancial nos objetivos de redistribuição de recursos (OLIVEIRA, 2009, p. 57). A Concertación, desde sua fundaçáo, apresentou programas de governo com apelo a diversos setores sociais, mas coerentes no que diz respeito ao objetivo de conjugar crescimento econômico com igualdade de oportunidades. Na prática, esse objetivo se traduziu em austeridade na política econômica e avanços graduais nas políticas sociais.

Portanto, a partir de sua reunificação e adesão à Concertación e ao governo Aylwin, o PS passou a equilibrar - nem sempre de maneira tranquila - seus objetivos eleitorais de poder via acesso aos cargos públicos no governo e de influência sobre políticas públicas. Seguindo os parâmetros definidos por Strøm (1990), é possível apreender que as concessôes programáticas exigidas pelos objetivos de curto prazo - obtençáo de cargos no governo e viabilidade eleitoral -, embora tenham permitido certa influência sobre as políticas públicas, ao longo prazo prejudicaram a capacidade do PS em garantir sua unidade interna e assegurar o apoio de setores de esquerda da população à Concertación. Ou, ao menos, favoreceu a evasão de lideranças que apelariam a esses setores nas eleiçôes de 2009.

Ao analisar a história recente do PS, identificam-se três momentos críticos gerados por choques externos - como definem Hamel e Janda (1994) 
- que impulsionaram a mudança partidária: o resultado das eleiçóes parlamentares de 1989, que inviabilizou a aliança entre o setor ortodoxo do PS e o PCCh; o início do governo Lagos, que frustrou expectativas de mudanças profundas na política social e econômica; e a abertura da possibilidade de levar à presidência Bachelet. As respostas organizacionais do PS foram as seguintes, respectivamente: unificação do PS e adesão à Concertación; surgimento de um campo pró-governo e moderação das demandas políticas da agremiação; e a formação de uma coalizáo interna entre os setores ortodoxo e reformado, que favoreceu a vinculação dos socialistas ao projeto da Concertación. Esses movimentos formam um processo de aproximação do PS à Concertación, seja em termos programáticos ou na ampliação da política de acordos.

A coalizão dominante do PS, ao impulsionar sua aproximação com a Concertación, pode ter considerado que os benefícios, em termos de chances de chegar ao poder, eram maiores do que os custos organizacionais implicados - como generalizam Harmel e Janda (1994, p. 278). Náo obstante, a mudança realizada importou um elevado custo no que diz respeito às capacidades organizacionais desenvolvidas pelo PS desde sua fundação. Roberts (1994) destaca como essas capacidades estavam relacionadas à possibilidade de absorver mudanças a partir do ambiente político e buscar alternativas na diversidade de suas forças internas para mudar a trajetória do partido.

Nesse contexto, notam-se ao menos três processos políticos que se opóem às referidas características históricas do PS: a necessidade de armar a lista das eleiçôes parlamentares, que exige rígidos acordos entre os partidos da Concertación; a política de consenso com o Congresso, que exige a pactuação com a oposição; e, especialmente, a emergência de uma coalizão dominante socialista disposta a utilizar mão de ferro para manter o partido na trilha aberta pela Concertación. A evolução do processo de aproximação com a Concertación parece ter sido capaz de interiorizar a rigidez do sistema político chileno no PS, incrementar a centralização das decisóes na direção partidária e anular os mecanismos de adaptaçáo destacados por Roberts (1994). A crise que levou à evasão de quadros partidários em 2009 pode ser compreendida como uma reação às mudanças organizacionais e programáticas do PS. Essas mudanças internas, por sua vez, estão conectadas às respostas que o partido escolheu dar aos desafios externos. Não foi um fato único e grave (choque externo) que 
O partido socialista chileno nos 20 anos de concertación: mudança organizacional, concessões programáticas e crise endógena | Augusto Neftali Corte de Oliveira

causou as rupturas no PS, mas uma situação de crise endógena decorrente das respostas organizacionais ao objetivo de manter e ampliar o espaço do partido na política chilena.

A literatura costuma encontrar nos desafios ou incertezas do sistema político e social os motivos que impulsionam a mudança partidária. No que concerne à atuação da Concertación, é lícita a aproximação da experiência partidária chilena com a tese desenvolvida por Katz e Mair (1995) a respeito da cartelização dos partidos políticos. Segundo os autores, em resposta à competição eleitoral em um ambiente em que os partidos perdem seus laços sociais e o apoio de grupos de interesses externos, as agremiaçóes tendem a reforçar a busca de recursos diretamente do Estado e a negociar a divisão de poder em coalizóes. A partir dos incentivos conjunturais e institucionais gerados no momento da transição para a democracia, a estratégia da Concertación consolidou um padrão de atuação no PS que colocou a competiçẫo eleitoral e a pauta programática de engajamento social em segundo plano.

A crise endógena do PS em 2009 foi uma resposta aos desdobramentos da mudança organizacional da agremiação, que impôs elevada rigidez organizacional e bloqueou as perspectivas de que o bem-sucedido projeto da Concertación pudesse ser inovado de maneira relevante. Talvez, inclusive, a candidatura Frei tenha sido interpretada como um retrocesso diante dos objetivos originais do PS. Ao optar por sair do partido e apresentar candidaturas próprias à presidência e ao Legislativo, os atores da crise de 2009 ampliaram a oferta de candidatos nas eleiçóes chilenas. As opções que encontravam-se canalizadas dentro da estrutura do PS e da Concertación sobre a indicaçáo de candidatos com propostas mais críticas ao governo, e ainda ligadas aos objetivos dos socialistas no período de transição, foram colocadas à disposição do eleitorado. Trata-se do movimento esperado por Kitschelt (2000, p. 168): quando os partidos se afastam de suas bases tradicionais em favor da cartelizaçáo, abrem espaço para o surgimento de novas opções partidárias e torna-se mais difícil manter a estabilidade da correlação de forças entre os atores já presentes no sistema político. Portanto, o resultado das mudanças no PS aumentou a competitividade do sistema político e também a incerteza sobre os futuros embates. 


\section{Considerações finais}

O momento da transiçáo para a democracia no Chile uniu o Partido Socialista às forças de centro do país. A participação do partido nos governos bem avaliados da Concertación - que cumpriram com relativo sucesso as propostas de obter desenvolvimento econômico, reduzir a pobreza e avançar na consolidaçáo da democracia - criou incentivos poderosos para que a coalizão fosse mantida. De fato, a trajetória do PS na nova democracia chilena é a de entrelaçamento do partido com a coalizão. Especialmente a partir do governo Lagos, os socialistas abriram mão de objetivos programáticos caros ao partido - como a ampliação do papel do Estado na provisão de bem-estar - para aderir ao governo e garantir a unidade da Concertación. $\mathrm{Na}$ verdade, a coalizáo se mostrou uma estratégia valiosa para os socialistas chegarem ao poder presidencial.

Não obstante, os compromissos exigidos para a manutenção da coalizão e para a participaçáo no governo cobraram um alto preço dos socialistas. Participar da Concertación exigiu que fossem suplantados os mecanismos de adaptação de trajetória e inovação endógena, muito valiosos para o partido ao longo de sua história. Como resultado, as divergências programáticas dos socialistas com a Concertación foram abafadas e as alternativas ao seu projeto não puderam ser seriamente consideradas. Ao fim do governo Bachelet, a direção do PS optou por apoiar a pré-candidatura do PDC para as eleições presidenciais, abrindo espaço para que novas e velhas lideranças, catalisando aquelas divergências programáticas, rompessem com o partido e a coalizão. Depois de ameaçar tomar da Concertación o lugar no segundo turno e conquistar a quinta parte do eleitorado nas eleiçóes presidenciais de 2009, a candidatura de Enríquez-Ominami representou a falta de renovaçáo do projeto programático da coalizáo e o bloqueio organizacional às opçóes do campo de esquerda do PS e da própria Concertación.

\section{Referências}

AHUMADA, J. Partido Socialista. El Mercurio, Santiago, 3 fev. 2005.

ALEMÁN, E.; SAIEGH, S. Legislative preferences, political parties, and coalition unity in Chile. Comparative Politics, Nova York, v. 39, n. 3, p. 253-272, 2007. 
O partido socialista chileno nos 20 anos de concertación: mudança organizacional, concessões programáticas e crise endógena | Augusto Neftali Corte de Oliveira

ALTMAN, D. Political recruitment and candidate selection: Chile, 1990 to 2006. In: SIAVELIS, P. M.; MORGENSTERN, S. (Org.). Pathways to power: political recritment and candidate selection in Latin America. Pennsylvania: Pennsylvania State University, 2008.

ANGELL, A. Party Change in Chile in Comparative Perspective. Revista de Ciencia Política, Santiago, Chile, v. 23, n. 2, p. 88-108, 2003.

ANGELL, A.; POLLACK, B. The Chilean presidential elections of 1999-2000 and democratic consolidation. Bulletin of Latin American Research, Liverpool, v. 19, n. 3, p. 357-378, 2000.

ANINAT, C.; LONDREGAN, J.; NAVIA, P.; VIAL, J.; DRAFT, T. Political institutions, policymaking processes, and policy outcomes in Chile. Washington: Inter-American Development Bank (Working Paper 3222), 2008. 52 p.

ARRATE, J.; et al. El Partido Socialista como Fuerza Popular. (Documento de discussão interna do Partido Socialista), Santiago, Chile, 7 p., 2007.

BIBLIOTECA DEL CONGRESO NACIONAL DE CHILE, 2009. Los candidatos a las parlamentarias 2009. Disponível em: <http://www.bcn.cl/especial-elecciones-2009-bcn/ elecciones-candidatos-2009/>. Acesso em: 25 jan. 2010.

BOENINGER, E. Políticas Públicas en Democracia: institucionalidad y experiencia chilena 1990-2006. Santiago: Uqbar, 2008.

CABELLO, F. Escalona lanza advertencia. Emol, 14 mar. 2009. Disponível em: <http://www.emol. com/noticias/nacional/detalle/detallenoticias.asp?idnoticia=348857>. Acesso em: 20 jan. 2010 .

CHILE. Sitio histórico electoral, 2009. Disponível em: <www.elecciones.gob.cl>. Acesso em: 20 fev. 2009.

CONCERTACIÓN DE PARTIDOS POR LA DEMOCRACIA. Programa de Gobierno Patrício Aylwin 1990-1994. Santiago: LaEpoca, 1989.

Programa de Gobierno: Para Crecer con Igualdad. Santiago, 1999. 64 p.

Programa de Governo 2006-2010. Santiago, 2005. 102 p.

Un Gobierno para los Nuevos Tiempos: Bases programáticas del Segundo Gobierno de la Concertación. Santiago, 1994. $136 \mathrm{p}$

CONCERTACIÓN y PC reconocen haber pactado en 25 comunas. El Mercurio, 29 jul. 2008.

EL SENADOR Navarro oficializa hoy su renuncia al partido socialista y se integra al MAS. El Mercurio, 6 nov. 2008a. 
ESCALONA pide Golpe de Timón a Pdte. Lagos, El Mercurio. 24 nov. 2000a.

FAZIO, H.; PRADA, M. Las políticas macroeconómicas en el sexenio Lagos. In: FAZIO, H. (Org.). El Gobierno Lagos: balance critico, Santiago: LOM, 2006.

FFRENCH-DAVIS, R.; GOMÁ, O. M. Las políticas económicas y sus efectos. In: MUÑOZ, O.; STEFONI, C. (Org.). El Período del Presidente Frei Ruiz-Tagle. Santiago: Flasco, 2003.

FOXLEY, A. La politica economica para la transición. In: MUNOOZ, O. Transición a la Democracia: marco politico y economico. Santiago: CIEPLAN, 1990.

GAJARDO, M. Educación, ciencia y cultura: políticas para la igualdad de oportunidades. In: MUÑOZ, O.; STEFONI, C. (Org.). El Período del Presidente Frei Ruiz-Tagle. Santiago: Flasco, 2003.

GAMBOA, R. Renovación Nacional. In: HUNEEUS, C.; BERRÍOS, F.; GAMBOA, R. (Org.). Las elecciones chilenas de 2005: partidos, coaliciones y votantes en transición. Santiago: Catalonia, 2007.

GAMBOA, R.; SALCEDO, R. El faccionalismo en el Partido Socialista de Chile 1990-2006: características y efectos políticos en sus procesos de toma de decisión. Revista de Ciencia Política, Santiago, v. 29, n. 3, p. 667-692, 2009.

GARRETÓN, M. A. La cuestión del régimen de gobierno en el Chile de hoy. In: LANZARO, J. (Org.). Tipos de presidencialismo y coaliciones políticas en América Latina. Buenos Aires: CLASCO, 2003.

GARRIDO, M.; GUERRA, M. El PS inicia fase de movilización social. El Mercurio, 2 abr. 2002. HARMEL, R.; JANDA, K. An Integrated Theory of Party Goals and Party Change. Journal of Theoretical Politics, Londres, n. 3, p. 259-287, 1994.

HUNEEUS, C. 2007. El Partido Demócrata Cristiano. In: HUNEEUS, C.; BERRÍOS, F.; GAMBOA, R. (Org.). Las elecciones chilenas de 2005: partidos, coaliciones y votantes en transición. Santiago: Catalonia, 2007.

HUNEEUS, C. El financiamiento de los partidos políticos y las campanas electorales en Chile. 1988. Disponível em: <http://www.iidh.ed.cr/comunidades/redelectoral/docs/red_publinea/ Financiacion/HUNNEUS.htm>. Acesso em: 3 jun. 2009.

Las coaliciones de partidos: ¿Un nuevo escenario para el sistema partidista chileno? Política, Santiago, n. 45, p. 67-86, 1988.

KATZ, R. S.; MAIR, P. Changing models of party organization and party democracy: the emergence of the Cartel Party. Party Politics, Washington, n. 1, p. 5-28, 1995. 
O partido socialista chileno nos 20 anos de concertación: mudança organizacional, concessões programáticas e crise endógena | Augusto Neftali Corte de Oliveira

KITSCHELT, H. Citizens, politicians, and party cartelization: political representation and state failure in post-industrial democracies. European Journal of Political Research, Essex, v. 37, n. 2, p. $149-179,2000$.

LAS GRANDES ALAMEDAS. Manifiesto las Grandes Alamedas: en el centenario del natalicio de Salvador Allende. Santiago, 2008. 22 p.

LEVINSKY, E. En temas políticos soy crítico del PS. El Mercurio, 5 maio. 2003

LOVEMAN, B. Chile: the legacy of Hispanic capitalism. Oxford: Oxford University Press, 2001. MARENCO, A.; SERNA, M. Por que carreiras políticas na esquerda e na direita não são iguais? Recrutamento legislativo em Brasil, Chile e Uruguay. Revista Brasileira de Ciências Sociais, São Paulo, v. 22, n. 64, p. 93-113, 2007.

MORGENSTERN, S. Explaining Legislative Politics in Latin America. In: NACIF, B

(Org.). Legislative politics in Latin America. Cambridge: Cambridge University Press, 2002.

NAVIA, P. Legislative Candidate Selection in Chile. In: SIAVELIS, P. M.; MORGENSTERN,

S. (Org.). Pathways to power: political recruitment and candidate selection in Latin America. Pennsylvania: Pennsylvania State University, 2008.

OLIVEIRA, A. N. C. de. Partidos e política social no Brasil e no Chile: PT e PS nas eleiçóes e no governo. Revista Debates, Porto Alegre, v. 3, n. 2, p. 39-67, 2009.

Os discursos programáticos dos partidos políticos na América Latina: identidade de classe e política econômica. Mediaçóes, Londrina, v. 16, n. 1, p. 201-221, 2011.

OPOSICIÓN contribuyó a Aprobación de Proyectos. El Mercurio, 20 jan. 2001.

PACTO con comunistas sólo benefició al PS. El Mercurio, 17 dez. 2001a.

PARTIDO SOCIALISTA. Congreso General Ordinario Programatico: resoluciones. La Serena, 1992. $143 \mathrm{p}$.

Documento Político Marco: el partido de la mayoría. Santiago, 2005. 13 p.

Plataforma electoral del Partido Socialista de Chile para las elecciones presidenciales y parlamentarias de 1989. Santiago, 1989. 8 p.

Resoluciones del Congreso General Extraordinario, Santiago, 1998. 14 p.

Resoluciones del XXVIII Congreso General Ordinario Salvador Allende Gossens del

Partido Socialista de Chile. Panimávida, 2008. 30 p. 
PRIETO, F. Lagos realiza primer cambio en gobierno tras elecciones parlamentarias. Emol, 26 dez. 2001. Disponível em: <http://www.emol.com/noticias/todas/detalle/detallenoticias. asp?idnoticia=74751>. Acesso em: 20 jan. 2010.

PS CRITICÓ baja Sensibilidad del Gbno. a Demandas Sociales. El Mercurio. 17 nov. 2000b.

RENUNCIA de Insulza abre debate sobre primarias. La Nacion, 6 jan. 2009.

ROBERTS, K. Renovation in the Revolution? Dictatorship, democracy, and political change in the Chilean left. Notre Dame. Kellogg Institute (Working Paper 203), 36 p., 1994.

SALCEDO, R.; FUENTE, G. Los partidos del bloque progresista. In: HUNEEUS, C.; BERRÍOS, F.; GAMBOA, R. (Org.). Las elecciones chilenas de 2005: partidos, coaliciones y votantes en transición. Santiago: Catalonia, 2007.

SALINAS, C. Escalona defiende la facultad de la Presidenta para nominar cargos. El Mercurio, 21 fev. 2006.

La experiencia en el bloque oriental. El Mercurio, 21 ago. 2000.

SCHERMAN, A. El gesto que no conformó a los partidos. El Mercurio, 2 mar. 2006.

SCULLY, T. R. The political underpinnings of economic liberalization in Chile. Notre Dame Kellogg Institute (Working Paper 211), 23 p., 1994.

SEHNBRUCH, K. SIAVELIS, P. The Bachelet administration: the normalization of politics? Berkeley. Center for Latin American Studies (LAS Working Papers), 31 p. 2009. Disponível em: <http://escholarship.org/uc/item/4kb4t7t9>. Acesso em: 8 mar. 2009.

SIAVELIS, M. Chile: las relaciones entre el poder ejecutivo y el poder legislativo después de Pinochet. In: LANZARO, J. (Org.). Tipos de presidencialismo y coaliciones políticas en América Latina. Buenos Aires: CLASCO, 2003.

SILVA, E. Chile. In: VANDEN, H.; PREVOST, G. (Org.). Politics of Latin America: the power game. Oxford: Oxford University Press, 2002.

SOCIALISMO anuncia lealtades y críticas. El Mercurio, 20 maio 2001B.

STRØM, K. A Behavioral Theory of Competitive Political Parties. American Journal of Political Science, Bloomington, v. 34, n. 2: 565-598, 1990.

TORREALBA, F. Enriquez-Ominami en su mensaje de renuncia. El Mercurio, 12 jun. 2009.

VALENZUELA, J. S. Democratización vía reforma: La expansión del sufragio en Chile. Buenos Aires: IDES, 1985. 
O partido socialista chileno nos 20 anos de concertación: mudança organizacional, concessões programáticas e crise endógena | Augusto Neftali Corte de Oliveira

The origins and transformations of the Chilean Party System. Notre Dame. Kellogg Institute (Working Paper 215), 60 p., 1995.

VILLAR, A.; COOK, M.; FUENTES, C. Funcionamiento interno de los partidos políticos em Chile: um diagnóstico. Santiago, Chile: Flacso, 2007.

WITKER, A. História Documental del PSCH 1933-1993: Forjadores - Signos de renovación. Santiago, Chile: IELCO, 1993.

26º CONGRESO del PS Sellará Reforma Interna. El Mercurio, 4 dez. 2000.

Recebido em: 29.09.2011

Aprovado em: 19.02.2013

The Socialist Party in the 20 years of Concertación: organizational change, programmatic concessions and endogenous crisis

\section{Abstract}

The paper provides an overview of the participation of Socialist Party in the 20 years of successive victories of Concertación in Chile's presidential elections. The research fits into the debate on the issue of the organization, objectives and party changes. Beside the academic literature on the subject, the article draws on journalistic periodicals to reconstruct the trajectory of the party. The main argument is that the organizational and programmatic changes in the Socialist Party, which are linked to the Chilean political system and to the goal of maintaining the Concertación, distorted the mechanisms of endogenous innovation of the party. This process is reflected in the secession of the left field of the Socialist Party and defeat of the Concentration's presidential candidate in 2009/2010.

Keywords: Chile. Socialist Party. Concertación. 